\title{
The Implementation of Augmented Reality-Based Learning in Computer Network System Courses
}

\author{
Nur Imansyah*1, Sri Handani $\mathbf{W}^{2}$ \\ 1,2Program Studi Teknik Informatika, Sekolah Tinggi Teknologi Bontang \\ E-mail : *1﹎._imansyah@yahoo.com, ${ }^{2}$ handaniwidiastuti@yahoo.com
}

\begin{abstract}
How to deliver teaching materials in lectures is one part that determines students understand the material presented, especially when lecture material is something that requires equipment that supports outdoor activities or requires practicum devices that are not possible to apply to the room for example is practicum about depicting Fresnel Zone and Sometimes monotonous delivery bores students so that they are not interested enough to have difficulty in understanding lecture material. One way that can be done to overcome this is by using visual equipment so that what is conveyed visually makes students interested in the material presented. Submission visually in the room is also a problem when the number of students is large. For that we need equipment that can provide information visually and is easy to use or carry that can stimulate the activities of students to interact. Augmented Reality is a visual model that can provide new experiences in interacting between real objects and virtual objects in the form of three dimensions, using augmented reality packaged as learning material can help students to understand teaching materials in lectures.
\end{abstract}

Keywords - Augmented Raeality, Utilzation Of Instructional Media

\section{INTRODUCTION}

Media in delivering material in education is an integral part of the implementation of teaching and learning. The way of delivering material in teaching and learning affects the desires and interests of students to understand the material presented. Bethany (2014) suggests that the learning process is the process of delivering messages/material from the message giver (teacher) to the message recipient (students). Changing material in the form of symbols, both verbal and non-verbal, is called encoding, and the interpretation of these symbols is called decoding. The decoding process is very dependent on educators in changing the material presented so that it can be understood by students. Sometimes even using visual media is not necessarily able to provide understanding to students about the material presented, especially subject matter that requires special equipment. Networking courses require inexpensive equipment when the material presented requires outdoor activity. Augmented Reality is an application that combines the real world with the virtual world in two-dimensional and threedimensional forms that are projected in a real environment at the same time. Augmented Reality is often referred to as augmented reality. Augmented Reality is often used in games and advertising media. Augmented Reality or Augmented Reality can provide new experiences in terms of the interaction between users and the media to be delivered, In the learning model that requires learning media that requires expensive equipment, added reality is a solution to overcome this. Students can understand a concept that is conveyed through interactive activities that exist in augmented reality. As in explaining how the picture of the Fresnel zone in computer network lecture material is certainly more interesting if it is presented visually using augmented reality. The added reality can be implemented into equipment that uses visual media such as computers and communication equipment so that students can easily use them and can do a practicum in virtual. 


\section{RESEARCH METHOD}

To be able to implement it into an Android device, it requires supporting hardware and software,

1. Hardware requirements are as follows:

- Android smartphone with camera features and Android 8.1 Oreo operating system

- A computer with a core i7 processor with a minimum of 4Giga memory.

2. Software requirements are as follows:

- The Vuforia API as a support module for Unity for Reality is added in this case as a marker identifier.

- 2018 version of Unity as an Augmented Reality processor and as a destination for the program to run into the Android operating system or other platforms.

- Visual Studio with C \# programming language as editor and compiler.

\subsection{System Design}

System design using a use case illustrates the interaction between the user and the Augmented Reality system as shown in the use case diagram in Figure 1 below:

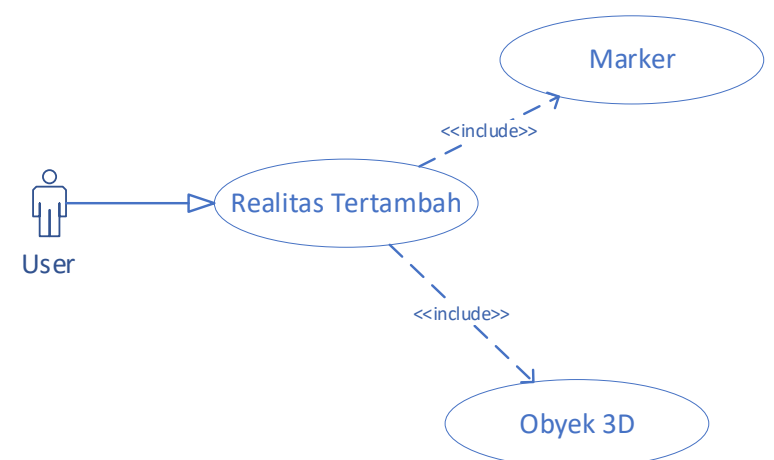

Figure 1. Augmented Reality Use Case Diagram

As seen in Figure 1, there is an Augmented Reality process by recognizing a marker as a place where 3D objects will be displayed further through the added Reality process, the merging between objects is presented to the user as a user. Furthermore, augmented reality will recognize two marker objects and replace the marker object with a wifi tower virtual object in the form of a 3D object. Then the process of drawing the Fresnel zone object that connects the two towers is carried out.

The following is a system design that will be carried out in the learning model using Augmented Reality. To be implemented into an Android device, several steps can be described in the form of a flowchart, as shown in Figure 2 below. 
ISSN : 1978 -8282, Online ISSN: 2655-4275

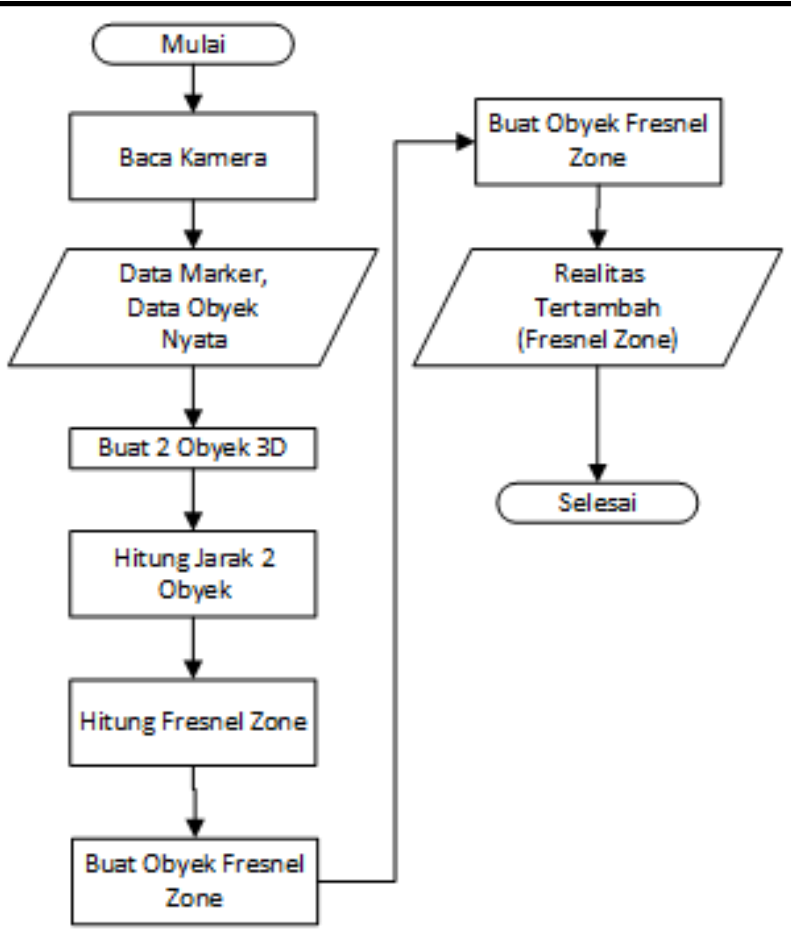

Figure 2. Fresnel Zone augmented Reality processes

\subsection{D Model Creation}

The 3D Model is built using 3D processing software, namely using a blender which is saved in the fbx format, 3D models are imported into Unity to manipulate interactions between 3D objects that will appear on markers in Augmented Reality.

\subsection{Marker Making}

Markers are made using vector image processing software which is then saved in JPG or PNG format. The marker object used is as shown in Figure 3 and Figure 4 below.

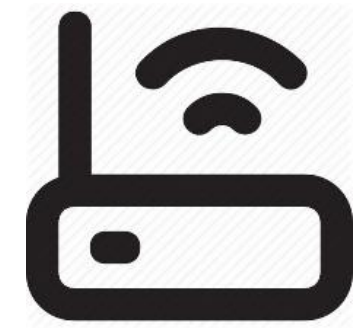

Figure 3. Object Marker Tower Wifi 1

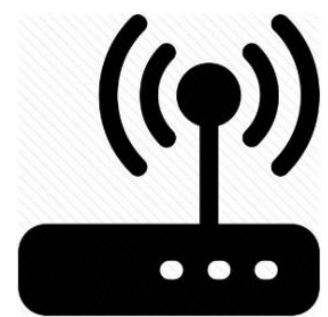

Figure 4. Object Marker Tower Wifi 2 
Furthermore, the marker image is uploaded to Vuforia to get Vuforia's API key which will be used in the Unity software for 3D object manipulation. as shown in Figure 5 below.

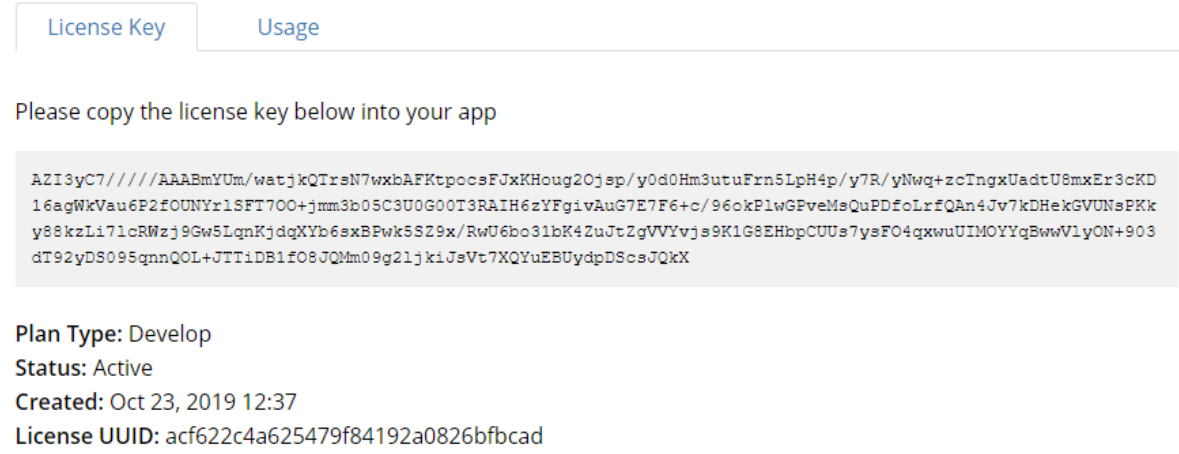

Figure 5. Vuforia Api Key

Next, download the Vuforia module which will become the target introduction library in unity. As seen in Figure 6 below.

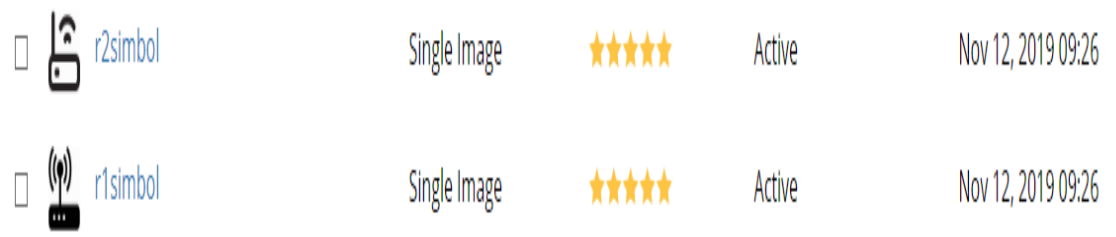

Figure 6. Vuforia Object Download

\subsection{Augmented Reality}

To create an added Reality Application, it is described as shown in Figure 7 below:

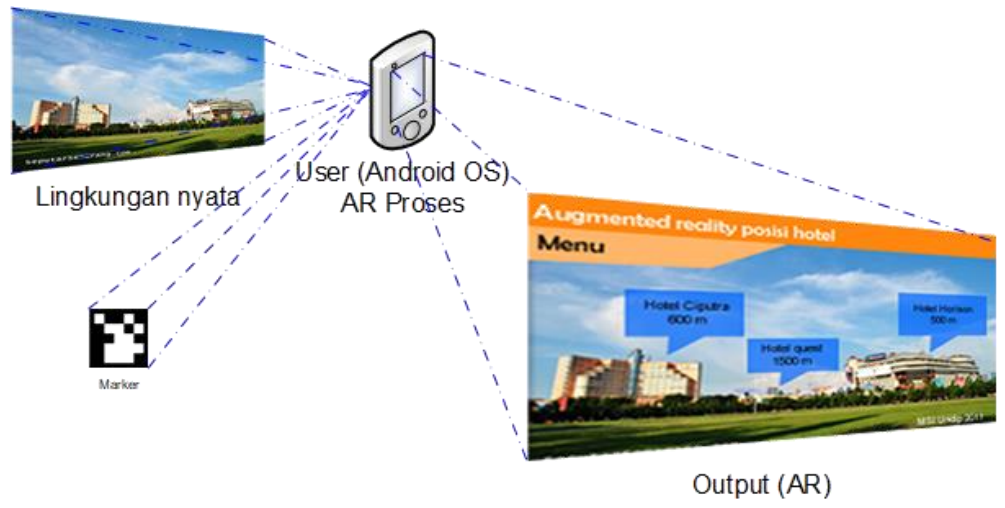

Figure 7. Augmented Reality-based Learning Architecture

As seen in the figure, the android device is a medium for process input and output from Augmented Reality.

1. Input

Through the camera on an Android device as a marker object input where 3D objects are placed to appear on the output. Cameras as input media for the real environment at that time. 


\section{Process}

In this section, the process of combining the real and virtual worlds ( $3 \mathrm{D}$ objects) is carried out. and the learning process that will be displayed, the learning process that will be displayed is a simulation of the Fresnel zone between two wifi tower objects. As an illustration, it can be seen in Figure 8 below:

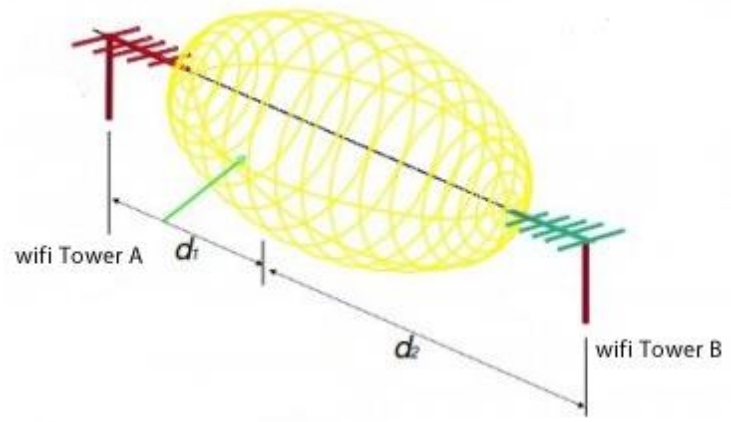

Figure 8. Fresnel Zone

With the Fresnel Zone formula as follows:

$$
F_{1}=17,3 \sqrt{\frac{d_{1} \cdot d_{2}}{f \cdot D}}
$$

Atau

$F_{1}=17,3 \sqrt{\frac{d}{4(f)}}$

Where :

- $\quad \mathrm{F} 1=$ Freznel Zone $(\mathrm{m})$

- $\mathrm{f}=$ frequency of work $(\mathrm{GHz})$

- $\mathrm{d} 1=$ the distance between Tx and the obstacle $(\mathrm{km})$

- $\quad \mathrm{d} 2=$ the distance between the Rx and the obstacle $(\mathrm{km})$

- $\quad \mathrm{D}=\mathrm{d} 1+\mathrm{d} 2=$ distance between Tx and Rx $(\mathrm{km})$

To be able to draw a 3D Fresnel Zone with the Bezier Quadratic Curve formula which has three control points, linear point to point interpolation of the two origin and end points of the curve. As seen in Figure 9:

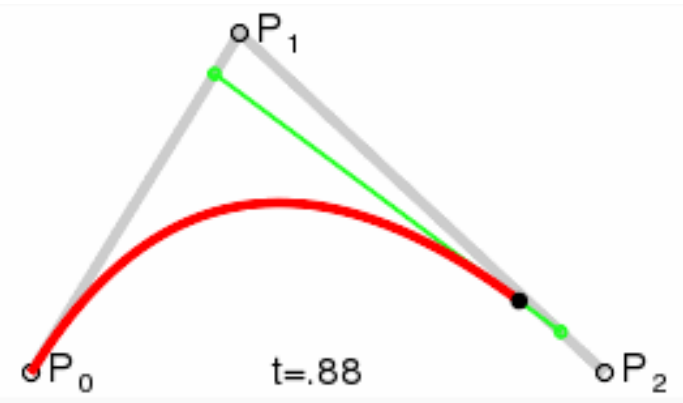

Figure 9. Berzier Curve

Where:

$$
B(t)=(1-t)^{2} P_{0}+2(1-t) t P_{1}+t^{2} P_{2}, 0 \leq t \leq 1
$$

$\mathrm{P} 0, \mathrm{P} 1, \mathrm{P} 2$ = bezier points

$\mathrm{P} 0, \mathrm{P} 1=$ origin and destination point 
After doing the system design, the next step is the coding process to place $3 \mathrm{D}$ objects using C \# programming as shown in Figure 10 below:

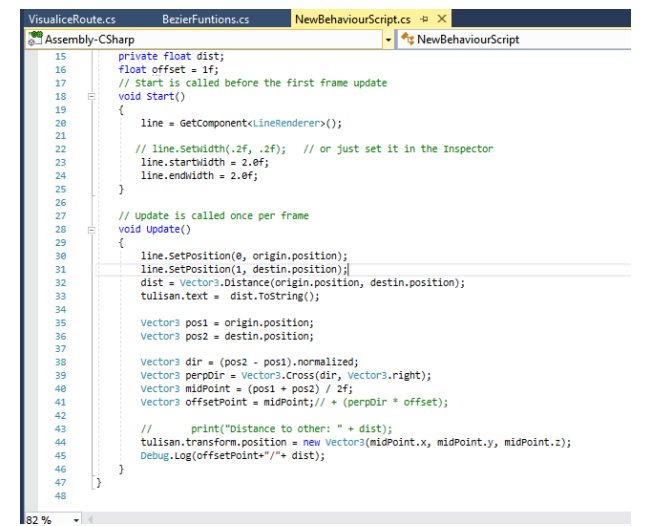

Figure 10. Visual Studio C\# Editor

In the defined program list, you can see the identification of objects in unity to get the position of object 1 as tower 1 and objects as tower 2 then place the 3D line image along tower 1 and tower 2 using the Line command.

- line.SetPosition(0, origin.position);

- line.SetPosition(1, destin.position);

The line command origin.position as the starting point of the Line of Sight line and destin.position as the end of the Line of Sight line. Next do a 3D Fresnel Zone wave image as seen in the Berzier Curve programming using the following Gizmo command:

- Gizmos.DrawLine(newVector3(Point1.position.x, Point1.position.y, Point1.position.z),

- new Vector3(Point2.position.x,

- Point2.position.y, Point2.position.z));

- Gizmos.DrawLine(newVector3(Point3.position.x, Point3.position.y, Point3.position.z),

- newVector3(Point4.position.x, Point4.position.y, Point4.position.z));

and the end point of the Fresnel zone is specified as $\mathrm{P}_{-} 0$ as Point3.position.x, $\mathrm{P}_{-} 1$ as Point4.position.y and, P_2 as Point4.position.z. shown in figure 9 .

\section{Output}

The output process is a display between real objects and virtual objects in the form of 3D wifi tower objects and an overview of the Fresnel zone on the screen of an Android device.

\section{RESULTS AND DISCUSSION}

The interface is designed to make it easier for users to use it, the interface in this application includes

\subsection{Main Menu Display}

On the main menu there are instructions for use and a start button when the user will start, as shown in the following figure 11 image: 


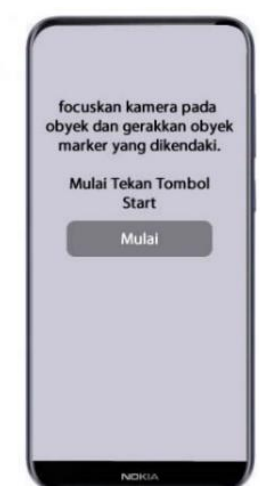

Figure 11. Main Menu Display

\subsection{Main Display}

In this section, images captured via the camera on an Android device are displayed, Furthermore, augmented reality will recognize two marker objects and replace the marker object with a wifi tower virtual object in the form of a 3D object. Then the process of drawing the Fresnel zone object that connects the two towers is carried out as shown in Figure 12.

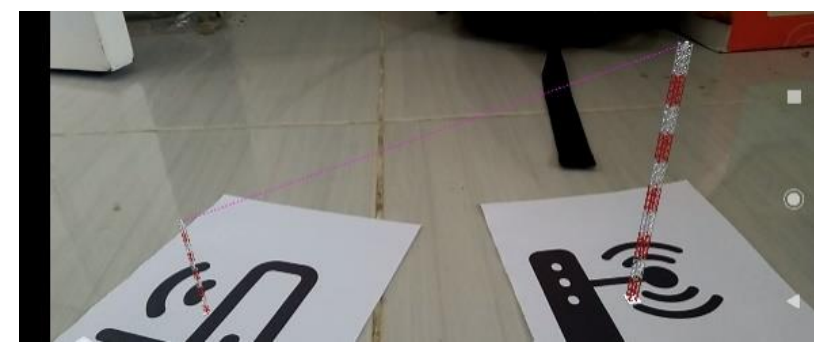

Figure 12. Enhanced Reality-Based Fresnel Zone application Main Views

In this section, you will see the object that will be captured by the Android device camera, which will then display the image of the wifi tower object from where the marker is located, for the tower display process and the information that appears will always be updated or dynamically change both the distance between 2 wifi towers, and information The Fresnel zone will appear when two objects can be recognized by the application, the two towers can be moved from one place to another by moving the marker so that 3D objects will always appear following the marker as well as objects from the Fresnel zone, as shown in Figure 13., the following :
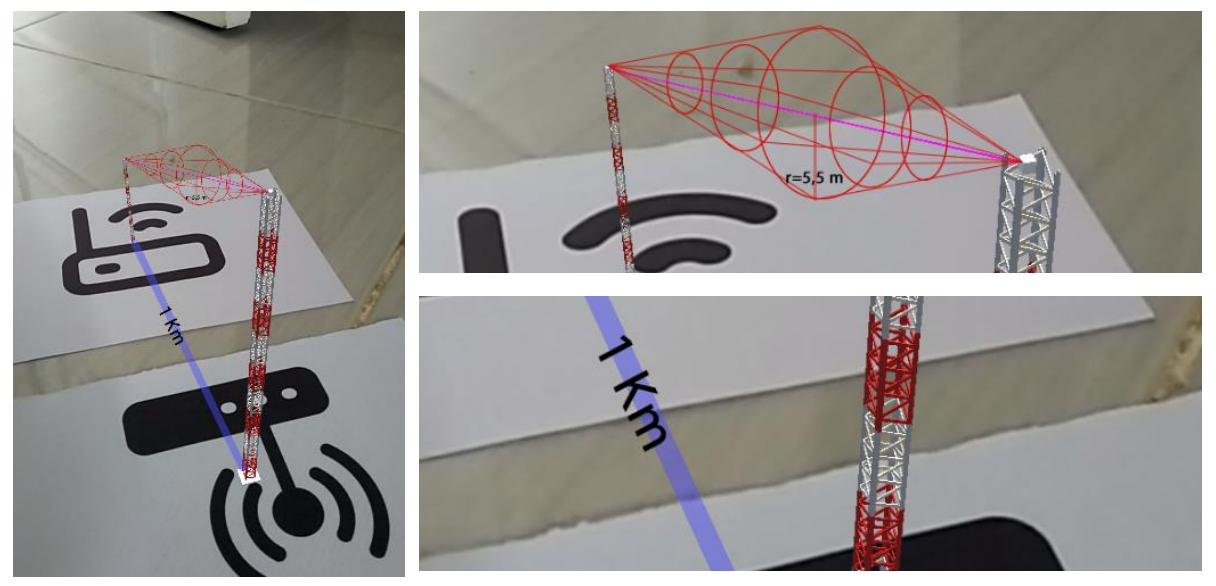

Figure 13. Freznel zone output using Augmented Reality 


\section{CONCLUSION}

By looking at the results obtained, it can be concluded that augmented reality provides another model for learning, especially in terms of visual presentation. Learning in this model requires the activity of the subject to carry out activities or for the interaction of the subject with the system so that changes can occur directly. In the added relation-based learning model, the subject will get new impressions and experiences in learning and more.

\section{SUGGESTED}

For further research, it can be carried out on dynamic marker objects without using static symbols. And further research can be developed in the form of a cloud so that it is not static in one material.

\section{REFERENCES}

[1] L. Hakim, "PENGEMBANGAN MEDIA PEMBELAJARAN PAI BERBASIS AUGMENTED REALITY," Lentera Pendidik., vol. 21, no. 1, p. 1, 2018.

[2] I. Mustaqim and N. Kurniawan, "PENGEMBANGAN MEDIA PEMBELAJARAN BERBASIS AUGMENTED REALITY,” Edukasi, vol. 1, no. 1, pp. 36-48, 2017.

[3] A. Kushwaha and V. Kushwaha, "Location Based Services using Android Mobile Operating System," Int. J. Adv. Eng. Technol., vol. 1, no. 7, pp. 14-20, 2011.

[4] A. M , Kumar, S. kumar M, Priya, and D. K, "A Survey of ARToolkitBased Augmented RealityApplications,” J. Comput. Appl., 2012.

[5] I. Mahendra, "IMPLEMENTASI AUGMENTED REALITY (AR) MENGGUNAKAN UNITY 3D DAN VUPORIA SDK," J. Ilmu Komput., 2017.

[6] M. Fernando, "Membuat aplikasi android augmented reality menggunakan vuforia sdk dan unity," Surakarta AR Online, 2013.

[7] N. Imansyah and S. H. Widiastuti, "Layanan Berbasis Lokasi Hotel Menggunakan Realitas Tertambah," J. Sist. Inf. BISNIS, 2017, doi: 10.21456/vol7iss2pp120-130.

[8] L. Suhery, "RANCANG BANGUN INFRASTRUKTUR WIRELESS DENGAN PENDEKATAN METODE LINE OF SIGHT," Rang Tek. J., 2018, doi: 10.31869/rtj.v1i2.766.

[9] A. Kapdi, "How To Work with Bezier Curve In Games with Unity," theappguruz, 2016. http://www.theappguruz.com/blog/bezier-curve-in-games. 